\title{
Prevalence and Risk Factors of Sexual Dysfunction in Patients with Chronic Heart Failure in Yaoundé, Cameroon
}

\author{
Jerome Boombhi ${ }^{1,2,}$, , Berthe Eteki ${ }^{1}$, Ba Hamadou ${ }^{1,3}$, Mazou Ngou Temgoua ${ }^{1}$, Donald Tchapmi ${ }^{1}$, \\ Alain Menanga ${ }^{1,2}$, Samuel Kingue ${ }^{1,2}$ \\ ${ }^{1}$ Department of Internal Medicine and Specialties, Faculty of Medicine and Biomedical Sciences, University of Yaoundé I, Yaoundé, \\ Cameroon \\ ${ }^{2}$ Cardiology Unit, General Hospital of Yaoundé, Yaoundé, Cameroon \\ ${ }^{3}$ Cardiology Unit, Central Hospital of Yaoundé, Yaoundé, Cameroon
}

\section{Email address:}

boombhijerome@yahoo.fr (J. Boombhi), bertheeteki@yahoo.com (B. Eteki),drhamadouba@yahoo.fr (Ba Hamadou), neurotemgoua@yahoo.fr (M. N. Temgoua),tn.donald@yahoo.fr (D. Tchapmi), amenanga@yahoo.fr (A. Menanga), samuel_kingue@yahoo.fr (S. Kingue)

${ }^{*}$ Corresponding author

\section{To cite this article:}

Jerome Boombhi, Berthe Eteki, Ba Hamadou, Mazou Ngou Temgoua, Donald Tchapmi, Alain Menanga, Samuel Kingue. Prevalence and Risk Factors of Sexual Dysfunction in Patients with Chronic Heart Failure in Yaoundé, Cameroon. Cardiology and Cardiovascular Research. Vol. 4, No. 1, 2020, pp. 17-21. doi: 10.11648/j.ccr.20200401.14

Received: February 5, 2020; Accepted: February 25, 2020; Published: March 10, 2020

\begin{abstract}
Heart failure is a major public health problem in sub Saharan Africa, associated with high morbidity and mortality. Sexual dysfunction contributes a lot to the burden of the disease. This complication is linked to the side effects of drugs, physical and psychological factors, and the coexistence of shared risk factors between heart failure and sexual dysfunction. Although patients with heart failure frequently report sexual disorders, few data are available in our context. This research seeks to determine the prevalence and risk factors of sexual dysfunction in patients with chronic heart failure in three reference hospitals of Cameroon. We carried out an analytical cross-sectional study over a period of four months (January to April 2018). All consenting patient with chronic heart failure aged 18 years and above were selected. Baseline sociodemographical and clinical characteristics were collected. The assessment of sexual function was made using a selfadministered questionnaire. Data analysis was done using the software IBM SPSS 23.0; the level of statistical significance was set at $\mathrm{p}<5 \%$. A total of 170 patients with chronic heart failure were recruited, the mean age was $60.46 \pm 10.66$ years old, with a female predominance (sex-ratio $=0.78$ ). The prevalence of sexual dysfunction was $57.7 \%$. The main sexual disorders were: Sexual desire disorders $(21.65 \%)$, vaginal lubrication disorders (20\%) in women, erectile disorders in men (17.3\%), orgasmic dysfunction (7.22\%), arousal disorders (4.44\%) and sexual satisfaction disorders (1\%). The independent risks factors of sexual dysfunction were: Female gender $(p=0.008)$, age $>60$ years $(p=0.001)$, hypertension $(p=0.0017)$, use of beta blockers $(\mathrm{p}=0.0081)$ and fear of heart attack $(\mathrm{p}<0,001)$. Sexual dysfunction is common in patients with chronic heart failure in our context. Indeed, it affects more than half of our study population $(57.7 \%)$ and is influenced by many factors.
\end{abstract}

Keywords: Sexual Dysfunction, Chronic Heart Failure, Sub-Saharan Africa

\section{Introduction}

Cardiovascular diseases (CVDs) are leading causes of death worldwide [1]. Heart failure (HF) is part of CVDs and it affects at least 26 million peoples worldwide [2]. It represents $37.7 \%$ cases of in-hospital admissions in Africa setting [3] and 33.3\% in Cameroon [4].
The spectrum of heart failure complications is very large; the most frequent are rhythm disorders, renal failure, venous thromboembolism, and stroke. As various chronic diseases, $\mathrm{HF}$ is also associated with sexual dysfunction (SD) [5]. This effect on sexual function is mostly explained by side's effects of drugs, physical and psychological factors [6, 7]. Another explanation is the fact that heart failure and sexual dysfunction 
share some similar risk factors like hypertension, diabetes and obesity [8-10]. The American Health Association (AHA) estimates that 60 to $87 \%$ of all patients with heart failure suffer from SD including a marked decrease in sexual interest and activity, with one quarter reporting cessation of sexual activity altogether. This condition contributes significantly to the alteration of the quality of life of these patients [11]. Also, this psychosocial aspect of patient's management is sometime neglected in our practice contributing therefore to the increase burden of the disease [12]. Although patients with heart failure frequently report sexual disorders, few data are available in our context. The purpose of this research was to determine the prevalence and risk factors of sexual dysfunction in Cameroonian patients with chronic heart failure.

\section{Material and Methods}

\subsection{Study Design, Setting and Participants}

This was a cross-sectional, analytical study carried out in three reference hospitals of Cameroon: General Hospital of Yaoundé (GHY), Central Hospital of Yaoundé (CHY) and Yaoundé University Teaching Center (YUTC) from January to April 2018. We consecutively enrolled all consenting patients with chronic heart failure aged above 18 years independently of their functional class which was evaluated by the New York Heart Association (NYHA) classification. We have excluded all participants with incomplete file.

\subsection{Data Collection}

Using a structured pilot-tested questionnaire, we interviewed all patients in external consultation unit of cardiology department who matched our inclusion criteria. We collected following socio-demographic data: age, sex, profession, marital status, education level, religion, ethnic origin. We also collected data on heart failure like: duration, type, functional class of NYHA, etiology, and Left ventricular ejection fraction (LVEF) of less than 3 months. For patient who did not have recent LVEF we realized a new ultrasonography to precise this data using value of Teicholz or Simplify Simpson's formula. The following cardiovascular risk factors were also assessed: Hypertension, current and past tobacco consumption, regular alcohol consumption, diabetes, dyslipidemia, obesity defined as a body mass index $\geq 30 \mathrm{~kg} / \mathrm{m}^{2}$, physical inactivity and stress assessed by Cohen Scale. Questions on sexuality were based on psychometrical analysis of Mozack and the diagnosis of sexual dysfunction based on Arizona Sexual Experience Scale (ASEX). ASEX is $\mathrm{s}$ a total of 5 questions ranging from 1 to 6 points, this scale evaluates: sexual desire, excitation, orgasm, satisfaction and erection for men or vaginal arousal for women. Sexual dysfunction was defined for a total score $\geq 19$, or $\geq 5$ for one question, or $\geq 4$ for 3 questions. Regular sexual activity was defined as havingat least three sexual intercourse per week.

\subsection{Statistical Analyses}

Data were analysed using IBM SPSS version 23.0. Means (standard deviations), medians, interquartile range (IQR) were used to summarize continuous variables, while frequencies and proportions were calculated for categorical variables. The Chi-square or Fisher's exact tests were used to compare categorical variables where applicable. The statistical significance was set at $\mathrm{p}<5 \%$.

\section{Results}

\subsection{Characteristics of the Study Participants}

We enrolled a total of 170 participants of whom 95 $(55.9 \%)$ were females (Table 1$)$. The mean age was $60.46 \pm$ 10.66 years with a range between $30-85$ years. Half of participants were $\geq 60$ years old; global heart failure with altered LVEF was the major type of heart failure. Amongst the cardiovascular risk factors, hypertension was mostly represented (Table 2).

Table 1. Demographic characteristics of participants.

\begin{tabular}{llll}
\hline Variables & Number (n=170) & Percentage (\%) \\
\hline Sex & Female & 95 & \\
& Male & 75 & 55.9 \\
Age & & 44.1 \\
& {$[18-30]$} & 0 & \\
& {$[30-40]$} & 6 & 0 \\
& {$[40-50]$} & 26 & 3.5 \\
& {$[50-60]$} & 41 & 15.3 \\
$\geq 60$ & 97 & 24.1 \\
Marital status & & 57.1 \\
& Married & 71 & \\
$\quad$ Non Married & 99 & 41.8 \\
Level of education & & 58.2 \\
& None & 29 & \\
& Primary & 69 & 17.1 \\
Secondary & 56 & 40.6 \\
University & 16 & 32.9 \\
\hline
\end{tabular}

Table 2. Clinical and paraclinical characteristics of the study population.

\begin{tabular}{|c|c|c|}
\hline Variables & Effective (n=97) & Percentage (\%) \\
\hline \multicolumn{3}{|l|}{ Type of Heart Failure } \\
\hline Right HF & 20 & 11.8 \\
\hline Left HF & 26 & 15.3 \\
\hline Global HF & 51 & 72.9 \\
\hline \multicolumn{3}{|l|}{ NYHA class } \\
\hline I & 11 & 11.3 \\
\hline II & 42 & 43.3 \\
\hline III-IV & 44 & 45.4 \\
\hline \multicolumn{3}{|l|}{ LVEF } \\
\hline Preserved & 18 & 18.6 \\
\hline Mid-range & 18 & 18.6 \\
\hline Altered & 61 & 62.8 \\
\hline \multicolumn{3}{|l|}{ Baseline heart disease } \\
\hline Hypertensive & 30 & 30.9 \\
\hline Ischemic & 12 & 12.4 \\
\hline Dilated & 22 & 22.7 \\
\hline Valvulopathy & 25 & 25.8 \\
\hline Toxic & 8 & 8.2 \\
\hline
\end{tabular}

\subsection{Prevalence of Sexual Dysfunction}

Among the 170 participants, 97 had regular sexual intercourse. 
The prevalence of sexual dysfunction was 57.7\% (56/97). The main sexual disorders were: Sexual desire disorders $(21.65 \%)$, vaginal lubrication disorders $(20 \%)$ in women, erectile disorders in men $(17.3 \%)$, orgasmic dysfunction $(7.22 \%)$, arousal disorders (4.44\%) and sexual satisfaction disorders (1\%).

\subsection{Risk Factors of Sexual Dysfunction}

The risk factors of SD in bivariate analysis were: class IIIIV of NYHA classification (OR: 3.15[1.22 - 8.32], p value $=0.008)$, use of beta-blockers (OR: 3.77 [1.26 - 12.65], $\mathrm{p}$ value $=0,0081$ ), hypertension (OR: 4.1 [1.53 - 11.5], $\mathrm{p}$ value $=0.0017)$, dyslipidemia (OR: 3.41 [1.06 - 12.85], p value $=0,023$ ), fear of cardiac attacks (OR: 6.82[2.54 18.68], $\mathrm{p}$ value $<0,001$ ) (Table 3 ).

After multivariate analysis only female gender $(\mathrm{p}=0.008)$, age $>60$ years $(p=0.001)$, hypertension $(p=0.0017)$, use of beta blockers $(p=0.0081)$, fear of cardiac attacks $(p<0,001)$, remained significantly associated with SD.

Table 3. Risk factors of sexual dysfunction on bivariate analysis.

\begin{tabular}{|c|c|c|c|c|c|}
\hline \multirow{2}{*}{ Variables } & \multicolumn{2}{|c|}{ Sexual dysfunction } & \multirow{2}{*}{ OR } & \multirow{2}{*}{ CI $(95 \%)$} & \multirow{2}{*}{ p value } \\
\hline & Yes $(n=56)$ & No $(n=41)$ & & & \\
\hline \multicolumn{6}{|l|}{ Age (years) } \\
\hline$[30-40]$ & $2(3 \%)$ & $4(10 \%)$ & 0.34 & $0.03-2.56$ & 0.212 \\
\hline$[40-50]$ & $10(18 \%)$ & $8(20 \%)$ & 0.89 & $0.52-4.63$ & 0.405 \\
\hline$[50-60]$ & $11(20 \%)$ & $12(29 \%)$ & 0.59 & $0.44-3.05$ & 0.672 \\
\hline$\geq 60$ & $33(59 \%)$ & $17(41 \%)$ & 2.02 & $0.34-2.1$ & $0.043 *$ \\
\hline \multicolumn{6}{|l|}{ Sex } \\
\hline Male & $24(43 \%)$ & $28(68 \%)$ & & & $0013 *$ \\
\hline Female & $32(57 \%)$ & $13(32 \%)$ & 0.35 & $0.14-0.87$ & $0.013^{*}$ \\
\hline \multicolumn{6}{|l|}{ Stage NYHA } \\
\hline Stage I & $4(7 \%)$ & $7(17 \%)$ & 0.37 & $0.08-1.62$ & 0.128 \\
\hline Stage II & $20(36 \%)$ & $22(54 \%)$ & 0.48 & $0.19-1.18$ & 0.078 \\
\hline Stage III- IV & $32(57 \%)$ & $12(29 \%)$ & 3.15 & $1.22-8.32$ & $0.008 *$ \\
\hline \multicolumn{6}{|c|}{ Duration of symptoms (years) } \\
\hline$<5$ & $32(57 \%)$ & $28(68 \%)$ & 0.62 & $0.24-1.56$ & 0.264 \\
\hline$[5-10]$ & $14(25 \%)$ & $6(15 \%)$ & 1.94 & $0.62-6.81$ & 0.213 \\
\hline$\geq 10$ & $10(18 \%)$ & $7(17 \%)$ & 1.06 & $0.32-3.62$ & 0.920 \\
\hline \multicolumn{6}{|l|}{ LVEF } \\
\hline Altered & $31(55 \%)$ & $30(73 \%)$ & 0.45 & $0.17-1.17$ & 0.073 \\
\hline Mid-range & $12(22 \%)$ & $6(15 \%)$ & 1.59 & $0.49-5.68$ & 0.395 \\
\hline Preserved & $13(23 \%)$ & $5(12 \%)$ & 2.18 & $0.64-8.49$ & 0.168 \\
\hline Loop diuretic & $35(62.5 \%)$ & $22(53.66 \%)$ & 1.44 & $0.59-3.53$ & 0.382 \\
\hline Thiazide diuretic & $21(37.5 \%)$ & $18(43.9 \%)$ & 0.77 & & 0.525 \\
\hline ACEIs & $45(80.36 \%)$ & $36(87.8 \%)$ & 0.57 & $0.14-1.99$ & 0.329 \\
\hline $\mathrm{CCB}$ & $38(67.86 \%)$ & $21(51.22 \%)$ & 2.01 & $0.81-5.01$ & 0.097 \\
\hline $\mathrm{ARB}$ & $26(46.43 \%)$ & $15(36.59 \%)$ & 1.5 & $0.61-3.73$ & 0.332 \\
\hline Digitalic & $29(51.79 \%)$ & $17(41.61 \%)$ & 1.52 & $0.62-3.71$ & 0.315 \\
\hline Beta-blockers & $22(39.29 \%)$ & $6(14.63 \%)$ & 3.77 & $1.26-12.65$ & $0.0081 *$ \\
\hline Statins & $12(21.43 \%)$ & $4(9.76 \%)$ & 2.52 & $0.68-11.55$ & 0.126 \\
\hline Anti-arythmic drugs & $7(12.5 \%)$ & $7(17.07 \%)$ & 0.69 & $0.19-2.56$ & 0.527 \\
\hline Alcohol & $23(41 \%)$ & $16(39 \%)$ & 1.09 & $0.44-2.7$ & 0.839 \\
\hline \multicolumn{6}{|l|}{ Tobacco } \\
\hline Active & $6(10 \%)$ & $1(3 \%)$ & 4.8 & $0.54-226.17$ & 0.120 \\
\hline Past-history & $16(29 \%)$ & $5(12 \%)$ & 2.88 & $0.88-10.97$ & 0.053 \\
\hline No history & $34(61 \%)$ & $35(85 \%)$ & 0.26 & $0.08-0.79$ & $0.008 *$ \\
\hline \multicolumn{6}{|l|}{ Weight } \\
\hline Normal & $39(70 \%)$ & $37(90 \%)$ & 0.25 & $0.06-0.87$ & $0.015^{*}$ \\
\hline Overweight & $8(14 \%)$ & $3(7 \%)$ & 2.11 & $0.46-13.1$ & 0.285 \\
\hline Obesity & $9(16 \%)$ & $1(3 \%)$ & 7.66 & $0.97-343.9$ & $0.029 *$ \\
\hline Hypertension & $30(53.57 \%)$ & $9(21.95 \%)$ & 4.1 & $1.53-11.5$ & $0.0017 *$ \\
\hline Diabetes & $13(23.21 \%)$ & $3(7.32 \%)$ & 3.83 & $0.94-22.25$ & $0.037 *$ \\
\hline Dyslipidemia & $18(32.14 \%)$ & $5(12.2 \%)$ & 3.41 & $1.06-12.85$ & $0.023 *$ \\
\hline Sedentary & $17(30 \%)$ & $18(44 \%)$ & 0.56 & $0.22-1.4$ & 0.170 \\
\hline \multicolumn{6}{|l|}{ Stress } \\
\hline Low & $21(38 \%)$ & $11(27 \%)$ & 1.64 & $0.63-4.39$ & 0.270 \\
\hline Moderate & $22(39 \%)$ & $22(53 \%)$ & 0.56 & $0.23-1.36$ & 0.160 \\
\hline High & $13(23 \%)$ & $8(20 \%)$ & 1.25 & $0.42-3.9$ & 0.662 \\
\hline Sexual intercourse & $25(45 \%)$ & $26(63 \%)$ & 0.47 & $0.19-1.15$ & 0.067 \\
\hline Fear of partner & $27(48 \%)$ & $9(22 \%)$ & 3.31 & $1.24-9.29$ & $0.0082 *$ \\
\hline Fear of heart attack & $40(71 \%)$ & $11(27 \%)$ & 6.82 & $2.54-18.68$ & $<0.001^{*}$ \\
\hline
\end{tabular}

*statistically significant.

ACEIs: Angiotensin Converting Enzyme Inhibitors, ARB: Angiotensin Receptor Blockers, CCB: Calcium Channel Blockers, CI: Confidence Interval, LVEF: Left Ventricular Ejection Fraction, OR: Odd Ratio. 


\section{Discussion}

Heart failure has many consequences that have been studied in literature [5]. But in our context data concerning sexual dysfunction in this population are scarce, leading us to conduct this study with the aim of determine prevalence and risk factors of sexual dysfunction in patient with chronic heart failure. This topic was important because in all culture sexuality has a great place in thewellbeingof an individual [12]. At the end of this study we found that: the prevalence of sexual dysfunction was $57.7 \%$, interesting various entities as sexual desire disorders, vaginal lubrication disorders, erection disorders, orgasmic dysfunction, arousal disorders and sexual satisfaction disorders. The independent risks factors of sexual dysfunction were: Female gender, age $>60$ years, hypertension, use of beta blockers, fear of cardiac attacks.

The high prevalence of sexual dysfunction is similar to the result of Hoesktra et al. in 2002 in Holland [13]. This high burden of sexual dysfunction in chronic heart failure is explained by psychological stress and hemodynamic alteration linked to the effect of drugs, co-morbidity or directly to the disease in these patients $[7,8]$. Contrary to previous studies [13-7], this sexual dysfunction was mostly frequent in female than male; this can be explained by the fact that our sample size was mainly constituted by older participants and post-menopausal women, knowing that menopause is associated with hormonal disorders that frequently alter sexual function.

Sexual desire disorders, vaginal lubrication and erection disorders were the most frequent sexual disorders in our population; Schwarz et al. in 2008 had similar findings concerning vaginal lubrication and erection disorders [7]. Jaarsma et al. in 2014 found like us that sexual desire disorders are predominant with a prevalence of $45 \%$ [14].

Hypertension was independently associated with sexual dysfunction in this population, like dyslipidemia and diabetes found in previous studies; this finding is explained by the direct effect of oxidative stress and atherosclerosis in vessels implicated in erection $[15,16]$. The use of beta-blockers (BB) was also an independent risk factor of sexual dysfunction because of the side effect of drug, mainly with non-selective beta-blockers [17]. But this result should be taken with caution because some patients were placed on cardio-selective beta-blockers and other on non-selectiveBB; we cannot therefore generalize this result. A psychological factor like fear of heart attack wasassociated with SD as explained by normal physiology of sexuality which placessexual desire as the first component of sexual intercourse process [18].

\section{Conclusion}

Sexual Dysfunction is frequent in patient with heart failure; in order to reduce its burden, psychological education is needed in patient with heart failure. Also, adequate management of other co-morbidities can result in significant improvement of the quality of life.

\section{List of Abbreviations}

AHA: American Heart Association; ASEX: Arizona Sexual Experience Scale; BB: Beta-Blockers; CHY: Central Hospital of Yaoundé; CVDs: Cardiovascular Disease; GHY: General Hospital of Yaoundé; HF: Heart Failure; IQR: Interquartile Range; LVEF: Left Ventricular Ejection Fraction; NYHA: New York Health Association; SD: Sexual Dysfunction; SPSS: Statistical Package of Social Sciences; YUTC: Yaoundé University Teaching Hospital.

\section{Declarations}

\section{Ethics Approval and Consent to Participate}

Ethical approval was obtained from the Institutional Review Board of the Faculty of Medicine and Biomedical Sciences, University of Yaoundé I. Also, administrative authorizations were obtained from the Directors of the General Hospital of Yaoundé, Central Hospital of Yaoundé and Yaoundé University Teaching Center prior to the start of the study. Written informed consent was obtained from all study participants who took part in this study.

\section{Consent for Publication}

Not applicable.

\section{Availability of Data and Materials}

The datasets used and analyzed during the current study are available from the corresponding author on reasonable request.

\section{Competing Interests}

The authors declare that they have no competing interests.

\section{Funding}

None.

\section{Authors' Contributions}

JB, BE, DT and MNT: study conception and design, data collection and analysis, interpretation of results, manuscript writing and critical revision. JB, BH, AM, SK: study conception and design, data collection and analysis, interpretation of results and critical revisions. All the authors read and approved the final version of the manuscript.

\section{Acknowledgements}

We would like to acknowledge the study participants for their commitment. The authors equally thank the administrative authorities of the Yaoundé General Hospital, 
Central Hospital of Yaoundé and Yaoundé University Teaching Center for granting them authorization to carry out this study.

\section{References}

[1] Reddy KS. Global Burden of Disease Study 2015 provides GPS for global health 2030. Lancet. 2016; 388 (10053): 14489.

[2] Savarese and G, Lund LH. Global public health burden of heart failure. Cardiac Failure Review 2017; 3 (1): 7-11. DOI: 10.15420/Cfr.2016:25:2.

[3] Thiam M. Insuffisance cardiaque en milieu cardiologique africain. Bull SocPatholExot. 2003; (221): 217-8.

[4] Boombhi J, Moampea M, Kuate L, Menanga A, Hamadou B, Kingue S. Clinical Pattern and Outcome of Acute Heart Failure at the Yaounde Central Hospital. Open Access Library Journal, 4: e3478. 2017; 4.

[5] Jaarsma T, Fridlund B, Mårtensson J. Sexual dysfunction in heart failure patients. Curr Heart Fail Rep. 2014; 11 (3): 3306.

[6] Randall AK, Bodenmann G. The role of stress on close relationships and marital satisfaction. Clin Psychol Rev. 2009 Mar 1; 29 (2): 105-15.

[7] Schwarz ER, Kapur V, Bionat S, Rastogi S, Gupta R, Rosanio $\mathrm{S}$. The prevalence and clinical relevance of sexual dysfunction in women and men with chronic heart failure. Int J Impot Res. 2008 Jan 20; 20 (1): 85-91.

[8] Vlachopoulos C, Jackson G, Stefanadis C, Montorsi P. Erectile dysfunction in the cardiovascular patient. Eur Heart J. 2013; 34 (27): 2034-46.
[9] Erectile Dysfunction and Coronary Risk Factors: Prospective Results from the Massachusetts Male Aging Study. Prev Med (Baltim) [Internet]. 2000 Apr 1 [cited 2017 Nov 25]; 30 (4): 328-38.

[10] Solomon H, Man JW, Jackson G. Erectile dysfunction and the cardiovascular patient: endothelial dysfunction is the common denominator. Heart. 2003 Mar 1; 89 (3): 251-3.

[11] Levine GN, Steinke EE, Bakaeen FG, Bozkurt B, Cheitlin MD, Conti JB, et al. Sexual Activity and Cardiovascular Disease A Scientific Statement From the American Heart Association. Circulation. 2012; 125: 1058-1072.

[12] Nicolai MPJ, Both S, Liem SS, Pelger RCM, Putter H, Schalij $\mathrm{MJ}$, et al. Discussing sexual function in the cardiology practice. Clin Res Cardiol 2013; 329-36.

[13] Hoekstra T, Lesman-Leegte I, Luttik ML, Sanderman R, van Veldhuisen DJ, Jaarsma T. Sexual problems in elderly male and female patients with heart failure. Heart. 2012 Nov 8; 98 (22): 1647-52.

[14] Jaarsma T. Sexual problems in heart failure patients. Eur J Cardiovasc Nurs [Internet]. 2002; 1 (1): 61-7.

[15] Girerd. La dysfonction érectile au cours des pathologies cardio-vasculaires. Praxis (Bern 1994). 2003 May 22; 92 (20): $950-5$.

[16] Droupy S. Épidémiologie et physiopathologie de la dysfonction érectile. Ann Urol (Paris). 2005 Apr 1; 39 (2): $71-84$.

[17] C. Pause, D Chatton MA. Effets secondaires médicamenteux et dysfonctions sexuelles. Revue Médicale Suisse [Internet]. 2000; 4 (20413).

[18] Cour F, Droupy S, Faix A, Methorst C, Giuliano F. Anatomie et physiologie de la sexualité. Progrès en Urol. 2013 Jul 1; 23 (9): 547-61. 